Mitteilungen der Österreichischen Geographischen Gesellschaft, 158. Jg. (Jahresband), Wien 2016, S. 10-11

\title{
Preface of the Managing Editor
}

\author{
Peter JoRDAN, Vienna [Wien]*
}

You will have very likely noticed it already, when you browsed through the sheets: This volume is the first to indicate an English secondary title ("Annals of the Austrian Geographical Society") and to present all subtitles, hints and texts functional in opening it up and subdividing it - also this preface and the guidelines for authors - consequently bilingually German/English. With this measure, we react to the growing number of scientific articles in English, even prevalent in the most recent volumes. This gave good reason to assume that many of our readers will find easier access to our journal via English than German.

A second motive to expand English in this way is the aspiration of our journal of being - although located in Austria and having a special focus on it - an international scientific journal with an audience also far beyond the German-speaking community.

A final reason was the decision of the Austrian Geographical Society's Executive Board to present the scientific articles of this volume for the first time open access, i.e. making them electronically available free of charge globally.

Thus, in contrast to other geographical journals - some of them rich in tradition like ours - in German-speaking countries and other smaller linguistic communities, we do not convert radically to English only, but navigate a balanced way attributing German language still major importance. We will, of course, publish also further on scientific articles in German, and the other sections of our journal (Reports and Notes, Personalia, Book Reviews, Communications of the Austrian Geographical Society) will anyway remain predominantly German. We have, however, to pay tribute to the fact that English has not only acquired the status of the by far most important global trade language, but also of the first language of sciences used in international conferences almost exclusively and in practically all publications aiming at international attention.

Even more serious, however, than the decision for an almost balanced use of German and English is the aforementioned intention to present the scientific articles of our volumes - starting with this volume - open access, since it means that scientific articles are available free of charge for everybody, can be downloaded as PDF and printed off from our journal's homepage (http://www.moegg.ac.at/), while members of our Society having subscribed for the Annals will still pay for them. They might indeed consider that as a kind of discrimination and wonder why they are still expected to pay for the Annals.

\footnotetext{
* Peter Jordan, PhD., Hon. and Assoc. Prof., Institute of Urban and Regional Research, Austrian Academy of Sciences, Postgasse 7/4/2, A-1010 Wien; email: peter.jordan@oeaw.ac.at, http://www.oeaw.ac.at/isr
} 
This was therefore not an easy decision for the Executive Board, and it has postponed it following an intensive discussion some years ago. It became, however, always more obvious that this measure is in fact unavoidable, should quality and standing as an internationally recognised scientific journal be maintained. Many institutions of scientific funding and research, to wit, are nowadays obliging their projectors and employees, respectively, to present their results open access. Journals not complying to these requirements must do without such authors and research results.

A second reason is the impact factor in the sense of a measuring of frequency to which articles of a journal are quoted in other publications. It indicates the 'visibility' of a journal, the extent to which it is regarded in the scientific community - and it depends in the first line on open access to a journal without any obstacles. A journal not meeting this requirement gets in the longer run behind the many others that are nowadays practising open access and will hardly be noticed anymore. Even articles of high quality 'will florish in secret' without open access.

Supporting by their membership fees persistence, quality and international standing of 'their' journal may therefore also be an argument for Society members, even when they have not the privilege of receiving its scientific articles exclusively anymore. It also remains the journal to which Society members as potential authors of scientific articles, reports and books to be reviewed enjoy easier access. Moreover, it remains their Society's communication medium - presenting reports on persons and events -, and Society members will stay the exclusive recipients of the printed volume with all its additional contents.

The present volume differs from earlier ones also by the fact that it lacks - exceptionally - an explicit thematical focus. It covers instead a wider field of various topics. Nevertheless, it focuses on some themes like "Migration and Integration", "Spatial Disparities" and "Space-related Identities" with three articles each. By the article "A comparison of content standards documents in China and the US", it presents a topic in the field of didactics of geography that may appear exotic in an Austrian journal, but hopefully inspires comparison with Austrian standards or standards in the entire German-speaking space. It would anyway be interesting to read such an article in one of the next issues of our journal.

From the international Editorial Board of the Annals comprising besides prominent geographers of the German-speaking community and Central Europe in the wider sense also many from other countries with a great geographic tradition, a replacement has to be reported as regards France: instead of André-Louis SANGUIN (Paris), to whom we are very grateful for his long-term engagement, Denise PUMAIN has declared herself ready to assume this function. She is a repeatedly awarded urban geographer at Sorbonne and has at the recent congress of the International Geographical Union (IGU) in Beijing presented a keynote on global urban development. As a peer- and book reviewer she has already been well-connected with our journal for years. 